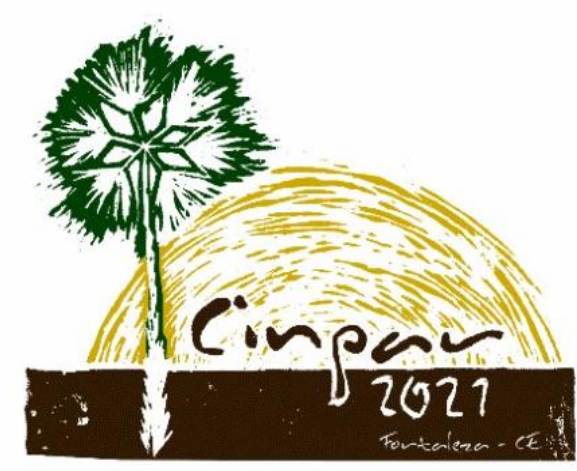

XVII Congresso Internacional sobre Patologia e

Reabilitação das Construções

XVII Congreso Internacional sobre Patología y Rehabilitación de las Construcciones

XVII International Conference on Pathology and Constructions Rehabilitation

FORTALEZA (Brasil), 3 a 5 de junho de 2021

https://doi.org/10.4322/CINPAR.2021.113

\title{
Análise das possíveis manifestações patológicas decorrente da não consideração da Interação Solo-Estrutura (ISE) em edificações de pequeno porte
}

\section{Analysis of possible pathological manifestations resulting from the non- consideration of Soil-Structure Interaction (ISE) in small buildings}

\author{
Mikhael Ferreira da Silva SANTOS ${ }^{1}$, Cláudio Vidrih FERREIRA ${ }^{2}$, Kelly Cristina Silva Santos ${ }^{3}$ \\ ${ }^{1}$ UFPE, Recife, Brasil, mikhael@ferreiraeng.com \\ 2 Instituto Vidrih, Bauru/SP, Brasil, vidrih@vidrih.com.br \\ ${ }^{3}$ UNIFACEMA, Caxias, Brasil, kellycsantos95@gmail.com
}

\begin{abstract}
Resumo: Os projetos estruturais, em sua grande maioria, parte da hipótese que a estrutura esteja apoiada sobre uma superfície rígida e inderfomável, isto é, apoios sem deslocamentos. Entretanto, na realidade, é impossível separar a infraestrutura (fundações e solo) da superestrutura (pilares, vigas, lajes etc.), pois ambas funcionam de maneira integrada. Em outras palavras, quando um solo recebe o carregamento proveniente das fundações, o mesmo se deforma e consequentemente haverá recalques que se refletirão na estrutura. Esse processo, basicamente, faz uma redistribuição dos esforços bem como gera uma tendência de uniformização dos recalques. A norma de fundações, NBR 6122:2019, trouxe a obrigatoriedade da análise da ISE em casos específicos: estrutura nas quais a carga variável é significativa; estruturas com mais de 55 metros de altura; estruturas cuja relação altura/largura seja superior a quatro; e projetos não convencionais. Não obstante, a norma é clara que não é somente nesses casos que deve considerar a ISE, mas em qualquer estrutura cuja deformabilidade possa influenciar na distruibuição dos esforços. Nesse panorama, o presente trabalho possui o escopo de analisar uma edificação residencial situada no município de Caxias, estado do Maranhão, buscando verificar a influência da ISE no seu projeto. Nesse trabalho também se pretende demonstrar quais as divergências ocorridas nas principais peças estruturais quando se considera a deformabilidade do solo na análise estrutural do edifício. A interação solo estrutura possibilita uma análise mais realística do que ocorre na realidade. Além de possibilitar erros contra a segurança da edificação, aplicar tais conceitos em projetos possibilita até edificações que antes não passariam nas normas, mas com a análise do solo em conjuntuta com a estrutura, se torna um projeto viável.
\end{abstract}

Palavras-chave: interação solo-estrutura; ISE; fundações; recalques.

Abstract: Structural projects, for the most part, start from the hypothesis that the structure is supported on a rigid and unbreakable surface, that is, supports without displacements. However, in reality, it is impossible to separate the infrastructure (foundations and soil) from the superstructure (pillars, beams, slabs, etc.), as both work in an integrated manner. In other words, when a soil receives the load from the foundations, it deforms and consequently there will be repression that will be reflected in the structure. This process basically redistributes efforts and generates a trend towards uniform settlement. The foundation standard, NBR 6122: 2019, made the ISE analysis mandatory in specific cases: structure in which the variable load is significant; structures over 55 meters high; structures whose height / width ratio is greater than four; and unconventional projects. Nevertheless, the rule is clear that it is not only in these cases that the ISE should be considered, but in any structure whose deformability may influence the distribution of efforts. In this 
context, the present work has the scope of analyzing a residential building located in the city of Caxias, state of Maranhão, seeking to verify the influence of ISE in its project. This work also intends to demonstrate the divergences that occurred in the main structural parts when considering the deformability of the soil in the structural analysis of the building. The solo structure interaction allows a more realistic analysis of what happens in reality. In addition to allowing errors against building security, applying such concepts to projects even makes buildings that would not have passed the standards before, but with the analysis of the soil in conjunction with the structure, it becomes a viable project.

Keyword: soil-structure interface; ISE; foundations; Settlements.

\section{Introdução}

Podemos dividir uma edificação em três partes: superestrutura, infraestrutura e terreno de fundação, conforme pode ser verificado na figura 01. A superestrutura corresponde à parte da edificação que será utilizada após sua construção, sendo composta por paredes, lajes, vigas e pilares. A infraestrutura é a parte constituinte pelos elementos que transferem o carregamento da superestrutura para o terreno de fundação e pelo cintamento. O terreno de fundação, por sua vez, possui o objetivo de absorver o carregamento proveniente da superestrutura.

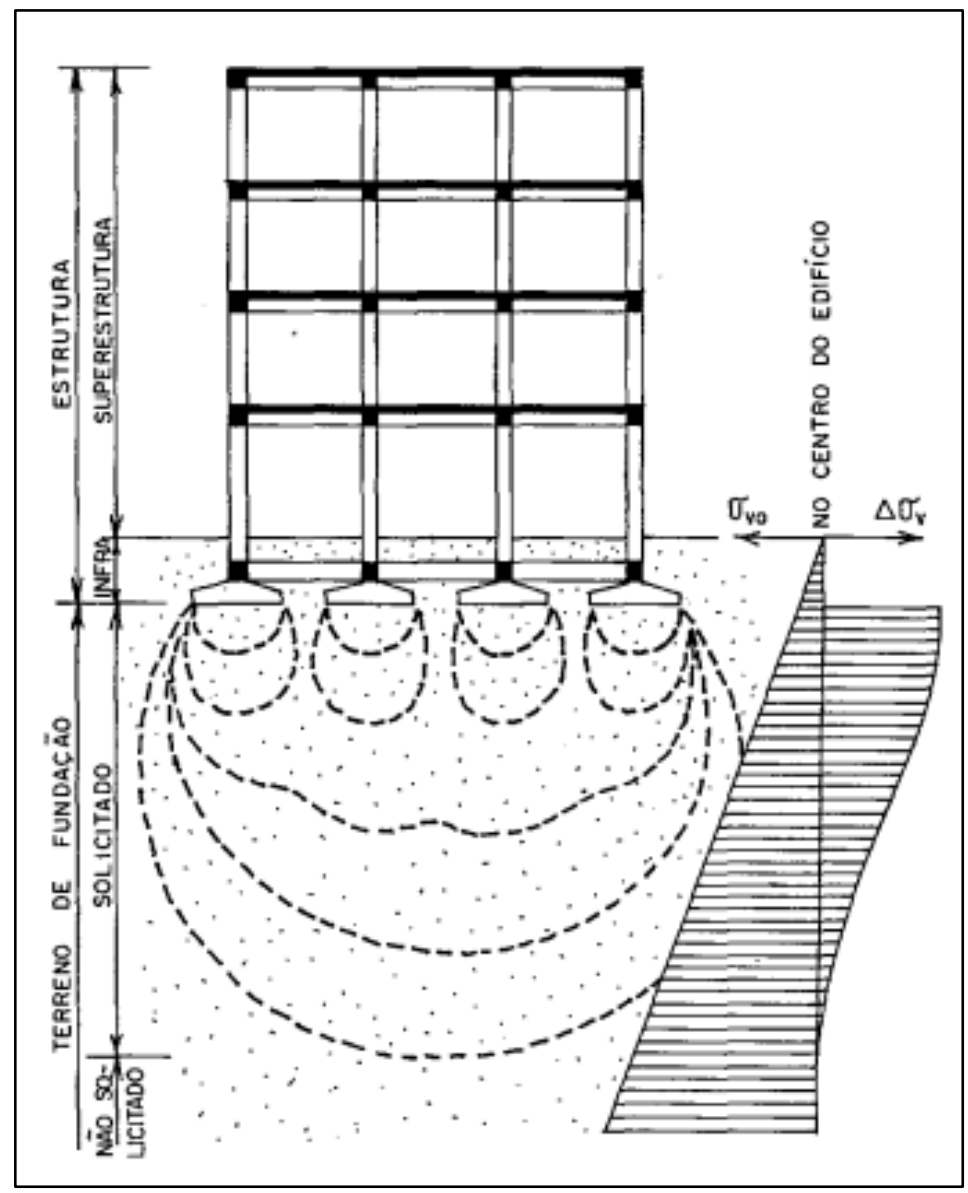

Figura 01. Superestrutura, infraestrutura e solo de fundação (GUSMÃO, 1990).

Na metodologia convencional de projeto (onde quase a totalidade dos projetos são pensados), admite-se a hipótese dos apoios serem indeslocáveis, isto é, sem recalques. A partir disso, o cálculo das cargas nas fundações e o dimensionamento dos elementos estruturais são feitos com base nessa hipótese.

Com o mesmo rigor de simplificação, as fundações são desenvolvidas levando em conta apenas as cargas nas fundações (obtida a partir do projeto estrutural com os apoios indeslocáveis) e as propriedades do terreno de fundação com seus recalques estimados a partir da simplificação indicada. 
Nas palavras de Gusmão (1990), isso faz com que haja um "fosso" entre o terreno de fundação e a estrutura (superestrutura e infraestrutura). A figura 02 também ilustra essa situação.

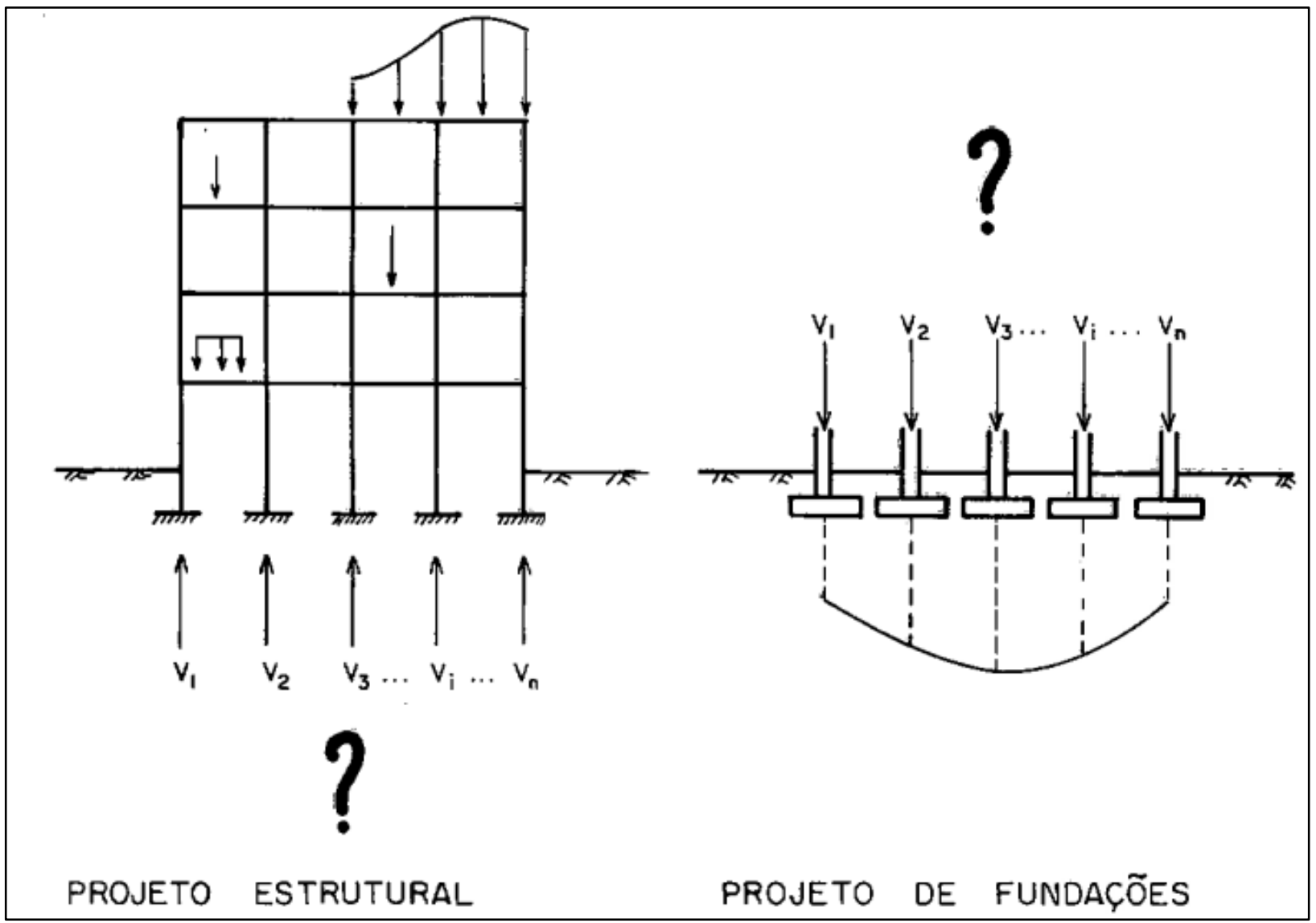

Figura 02. "Fosso" existente entre a estrutura e o terreno de fundação (GUSMÃO, 1990).

Até a penúltima versão da norma de fundações, NBR 6122:2010, não havia a obrigatoriedade de considerar a interação solo estrutura nas edificações, o projetista teria apenas que avaliar a necessidade do estudo. Não obstante, a NBR 6122:2019 trouxe no seu item 5.5, trouxe a obrigatoriedade da interação solo estrutura nos seguintes casos:

i. Estrutura nas quais a carga variável é significativa em relação à carga total, tais como silos e reservatórios;

ii. Estruturas com mais de 55 metros de altura, medida do térreo até a laje de cobertura do último piso habitável;

iii. Relação altura/largura (menor dimensão) superior a quatro;

iv. Fundações ou estruturas não convencionais.

Nesse panorama, o presente trabalho possui o escopo de analisar uma edificação residencial situada no município de Caxias, estado do Maranhão, buscando verificar a influência da ISE. Nesse trabalho, também, se pretende demonstrar quais as divergências ocorridas nas principais peças estruturais quando se considera a deformabilidade do solo na análise estrutural do edifício. A interação solo estrutura possibilita uma análise mais realística do que ocorre na realidade. Além de possibilitar erros contra a segurança da edificação, aplicar tais conceitos em projetos possibilita até edificações que antes não passariam nas normas, mas com a análise do solo em conjunto com a estrutura, se torna um projeto viável. 


\section{Metodologia de análise da interação solo-estrutura aplicada em fundações superficiais}

Devido à importância do tema, vários trabalhos foram publicados, atraindo a atenção de grande número de pesquisadores brasileiros nas últimas décadas. Mesmo assim, a interação solo estrutura continua sendo negligenciada, nem perto de haver uma padronização de métodos para chegar a resultados satisfatórios. Diversos trabalhos pioneiros contribuiram para o tema, como Meyerhof (1953), Chamecki (1954) e Goshy (1978). Em especial o trabalho de Chamecki (1954) apresentou uma solução bastante consistente, sendo que os recalques calculados costumam se aproximar bastante dos recalques medidos.

Aoki e Cintra (2003) resumem um roteiro que costumam adotar em estudos de interação solo-estrutura, cuja concepção baseou-se na proposta de Chamecki (1954). A metodologia pode ser descrita da seguinte forma:

i. Inicialmente calcula-se a carga nos pilares considerando os apoios como indeslocáveis;

ii. A partir dessas cargas, calculam-se os recalques considerando a rigidez da estrutura nula (sem considerar a superestrutura na estimativa dos cálculos), obtendo-se a bacia inicial de recalque;

iii. Assim, obtém-se os coeficientes de mola através da divisão das cargas pelos recalques para cada um dos pilares e depois recalcula as cargas nos pilares considerando a estrutura sobre apoios elásticos (sendo considerada a $1^{\circ}$ interação);

iv. A partir da $1^{\circ}$ interação, recalculam-se os novos recalques considerando a rigidez nula da estrutura, obtendo a nova bacia de recalques;

v. Avaliam-se novamente os novos coeficientes de mola a partir da bacia de recalque encontrada no item anterior, processando novamente a estrutura;

vi. O processo é interativo até que se atinja a convergência desejada.

Nesse sentido, o presente trabalho considera a metodologia supracitada, conforme descrito por Aoki e Cintra (2003), seguindo a ideia dos passos anteriores.

Para processamento estrutural da edificação, o presente trabalho utilizou um software baseado em Método dos Elementos Finitos (MEF) desenvolvida pela AltoQi, sendo o eberick em sua versão 2021. A partir desse software, foi possível processar a estrutura, dimensionar os elementos estruturais e simular as molas, conforme hipótese de Winkler.

Para estimativa dos recalques, utilizou a equação desenvolvida por Perloff (1975) com base na teoria da elasticidade que fornece os recalques imediatos para o caso de meio contínuo, elástico, homogêneo, isotrópico e semi-infinito. A equação (1) ilustra a formulação:

$$
W_{i}=\sigma \cdot B \cdot\left(\frac{1-v^{2}}{E_{S}}\right) \cdot I_{w}
$$

Onde:

$\mathrm{B}=$ menor dimensão da base da sapata;

$\mathrm{v}=$ coeficiente de poisson do solo;

$I_{W}=$ fator de influência, que depende da forma e da rigidez da sapata;

$E_{S}=$ módulo de elasticidade do solo.

A estimativa do módulo de elasticidade do solo foi feita baseada no trabalho de Conde de Freitas et al. (2012), sendo uma correlação baseada no $\mathrm{N}_{60}$ (corresponde a $60 \%$ da energia teórica do ensaio SPT) para solos arenosos, conforme equações (2) e (3). Para o coeficiente de Poisson foi considerado o valor de 0,3 para as areias e 0,49 para as argilas.

$$
\begin{gathered}
E_{S}=8000 \cdot N_{60}^{0,8}(k P a) \\
N_{60}=1,37 N_{S P T}
\end{gathered}
$$




\section{Característica da edificação analisada}

A edificação analisada é de tipologia comercial, sendo composta de 02 (dois) pavimentos: térreo e superior. Se trata de uma edificação regular de médio padrão. Toda estrutura foi projetada em concreto armado, alvenaria de blocos cerâmicos com lajes treliçadas. A figura 03 ilustra o projeto arquitetônico desenvolvido para a edificação.

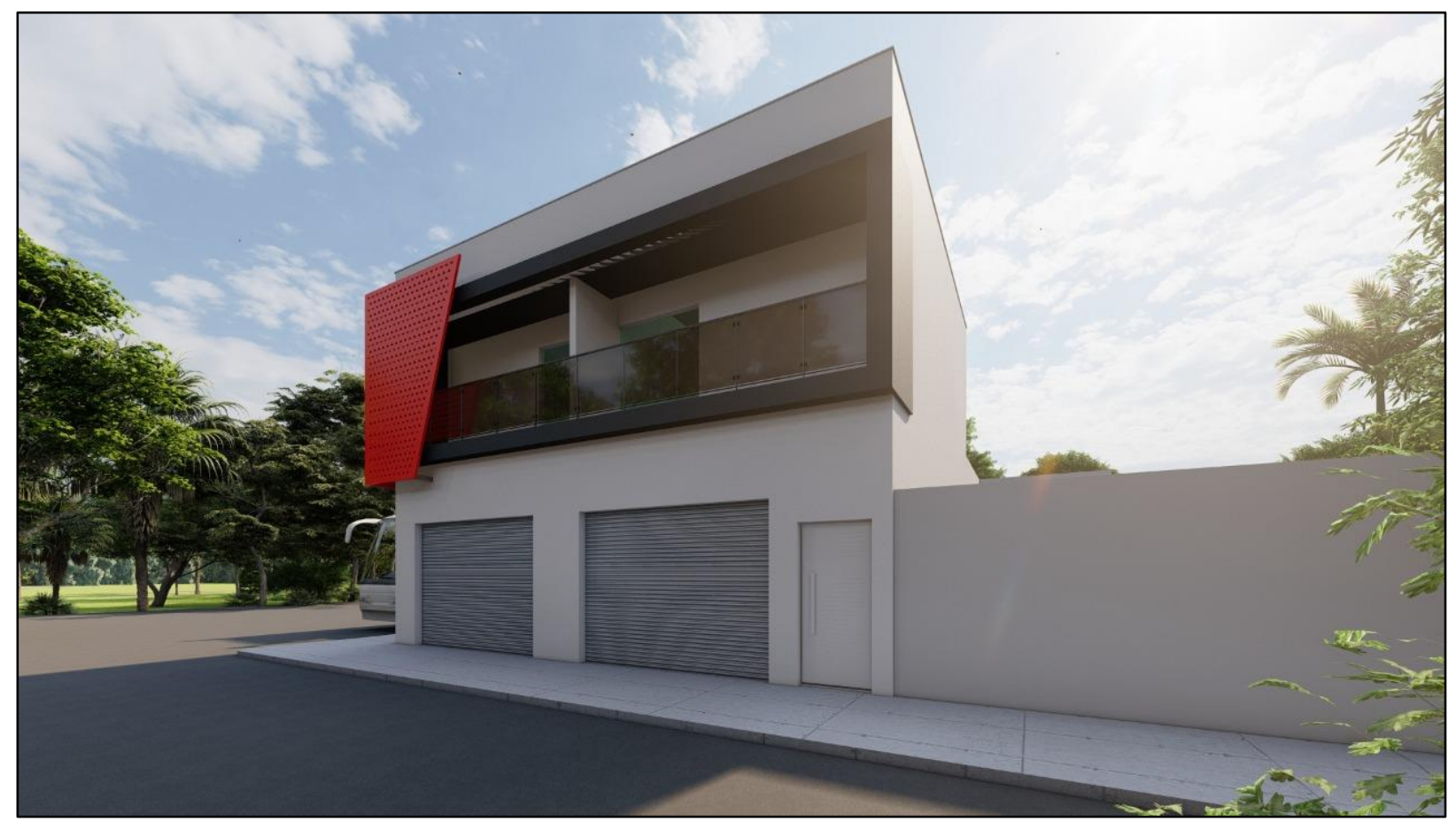

Figura 03. Projeto arquitetônico desenvolvido.

Para o projeto de fundações, foi realizado um ensaio de sondagem (SPT) para caracterizar o solo de fundação. A figura 04 ilustra parte do relatório. É importante salientar que o solo apresenta resistência à penetração significativa nas camadas iniciais.

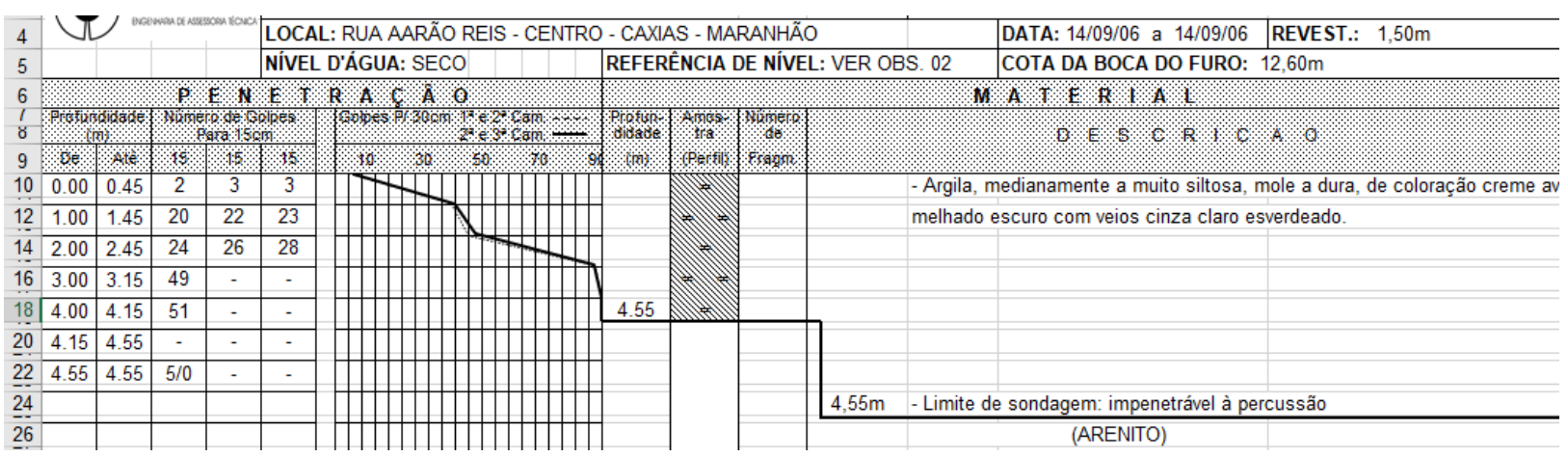

Figura 04. Relatório do sondagem de simples reconhecimento (SPT).

Na cidade em estudo, é comum o uso de fundação superficial nas edificações existentes devido a alta resistência das camadas iniciais do solo.

Alguns locais, já definidos, conforme pode ser verificado no trabalho de Santos et al (2018), que realizou uma síntese de caracterização dos ensaios SPT realizados nos municípios de Caxias, Maranhão, e Teresina, Piauí. Em caxias, especialmente, há dois locais constatados com a presença de argila mole, ambos em locais próximo a rochas expostas. 


\section{Resultado e discussão}

Conforme metodologia, inicialmente a estrutura foi modelada considerando os apoios indeslocáveis. A figura 05 ilustra a modelagem da estrutura conforme exigências arquitetônicas.

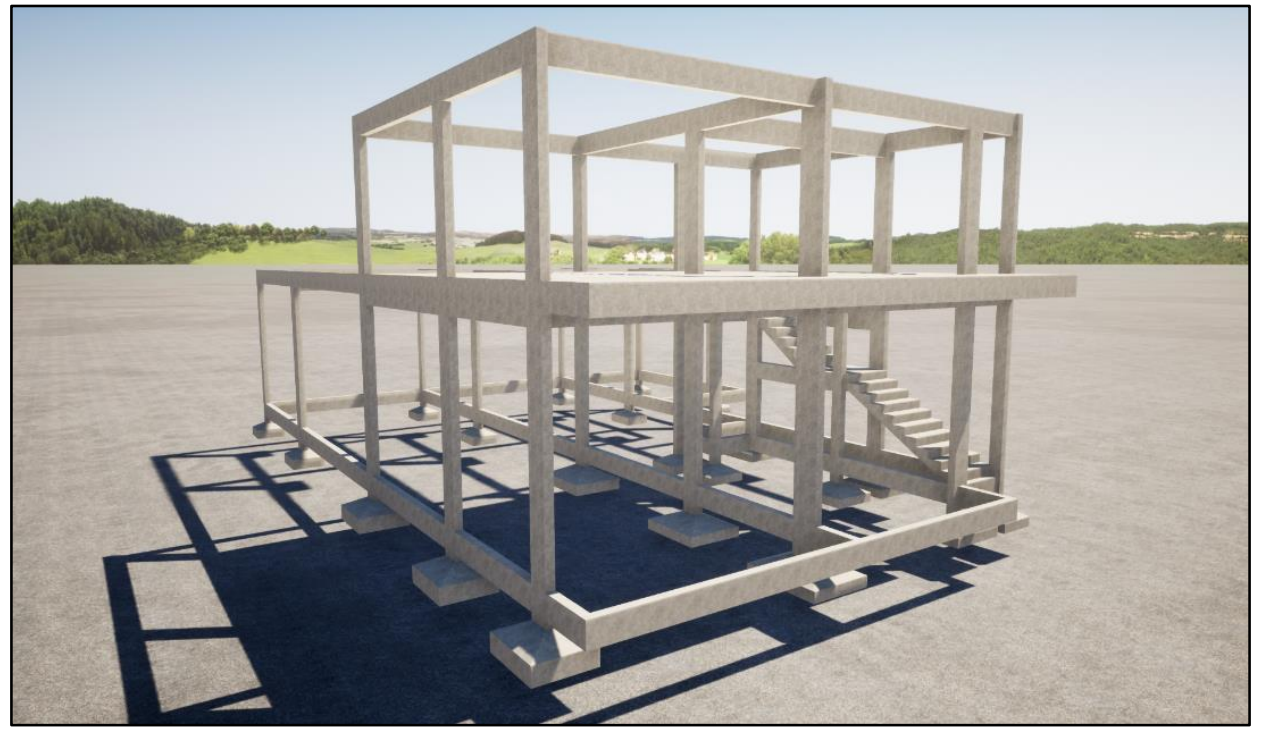

Figura 05. Modelagem da estrutura

Com base no relatório de cargas que chegaram na edificação, foi possível estimar os recalques e iniciar o processo interativo. O processo interativo convergiu com somente uma interação, isso devido as característica do solo com resistência elevada e recalques pequenos. A tabela 01 ilustra as cargas e recalques considerado em cada uma das interações propostas, conforme pode ser verificado a seguir.

Tabela 01. Comparativo das interações encontradas.

\begin{tabular}{|c|c|c|c|c|c|}
\hline Pilar & $\begin{array}{c}\text { Nk (kN) - apoio } \\
\text { indeslocável }\end{array}$ & Recalque (mm) & $\begin{array}{c}\text { Coeficiente de mola } \\
\text { vertical }(\mathbf{k N} / \mathbf{m})\end{array}$ & $\begin{array}{c}\text { Nk (kN) - apoio } \\
\text { elástico }\end{array}$ & $\begin{array}{c}\text { Diferença } \\
\text { (\%) }\end{array}$ \\
\hline P1 & 118.3 & 0.725 & 163251.49 & 118.2 & 0.08 \\
\hline P2 & 196.4 & 1.203 & 163251.49 & 193.8 & 1.32 \\
\hline P4 & 120.4 & 0.843 & 142845.06 & 120.7 & -0.25 \\
\hline P5 & 120.1 & 0.736 & 163251.49 & 120.8 & -0.58 \\
\hline P6 & 179.5 & 1.100 & 163251.49 & 180.9 & -0.78 \\
\hline P7 & 143 & 0.876 & 163251.49 & 140.7 & 1.61 \\
\hline P8 & 135.2 & 0.828 & 163251.49 & 136.4 & -0.89 \\
\hline P9 & 251.1 & 1.367 & 183657.93 & 247.7 & 1.35 \\
\hline P10 & 148.7 & 0.911 & 163251.49 & 143 & 3.83 \\
\hline P11 & 72.9 & 0.510 & 142845.06 & 78.4 & -7.54 \\
\hline P12 & 38.3 & 0.235 & 163251.49 & 38.2 & 0.26 \\
\hline P13 & 63 & 0.386 & 163251.49 & 62.8 & 0.32 \\
\hline P14 & 57 & 0.349 & 163251.49 & 56.8 & 0.35 \\
\hline P15 & 31.8 & 0.195 & 163251.49 & 32.1 & -0.94 \\
\hline P16 & 54.6 & 0.334 & 163251.49 & 54.9 & -0.55 \\
\hline P17 & 56.1 & 0.344 & 163251.49 & 56.8 & -1.25 \\
\hline P18 & 69.6 & 0.426 & 163251.49 & 69.5 & 0.14 \\
\hline P19 & 60.2 & 0.311 & 193861.15 & 60.2 & 0.00 \\
\hline P20 & 121.2 & 0.742 & 163251.49 & 119.7 & 1.24 \\
\hline P21 & 103.6 & 0.725 & 142845.06 & 102.3 & 1.25 \\
\hline
\end{tabular}

Título abreviado do artigo, usando no máximo 100 caracteres incluindo os espaços em branco 
Conforme é possível verificar, devido a natureza das cargas, tipo de empreendimento e característica dos solos, o recalque estimado máximo foi de $1,37 \mathrm{~mm}$ inerente ao pilar P9 (sendo o pilar com maior carga do projeto). Os valores convergiram na $1^{\circ}$ interação, sendo que a maior diferença se encontra no pilar P11, equivalente a 7,54\%. As figura 06 e 07 ilustram, na devida ordem os momentos fletores do pórtico para a hipótese de apoio indeslocável e apoio elástico. Conforme verificado, os momentos máximo e mínimos foram alterados com diferenças de $3,63 \%$.

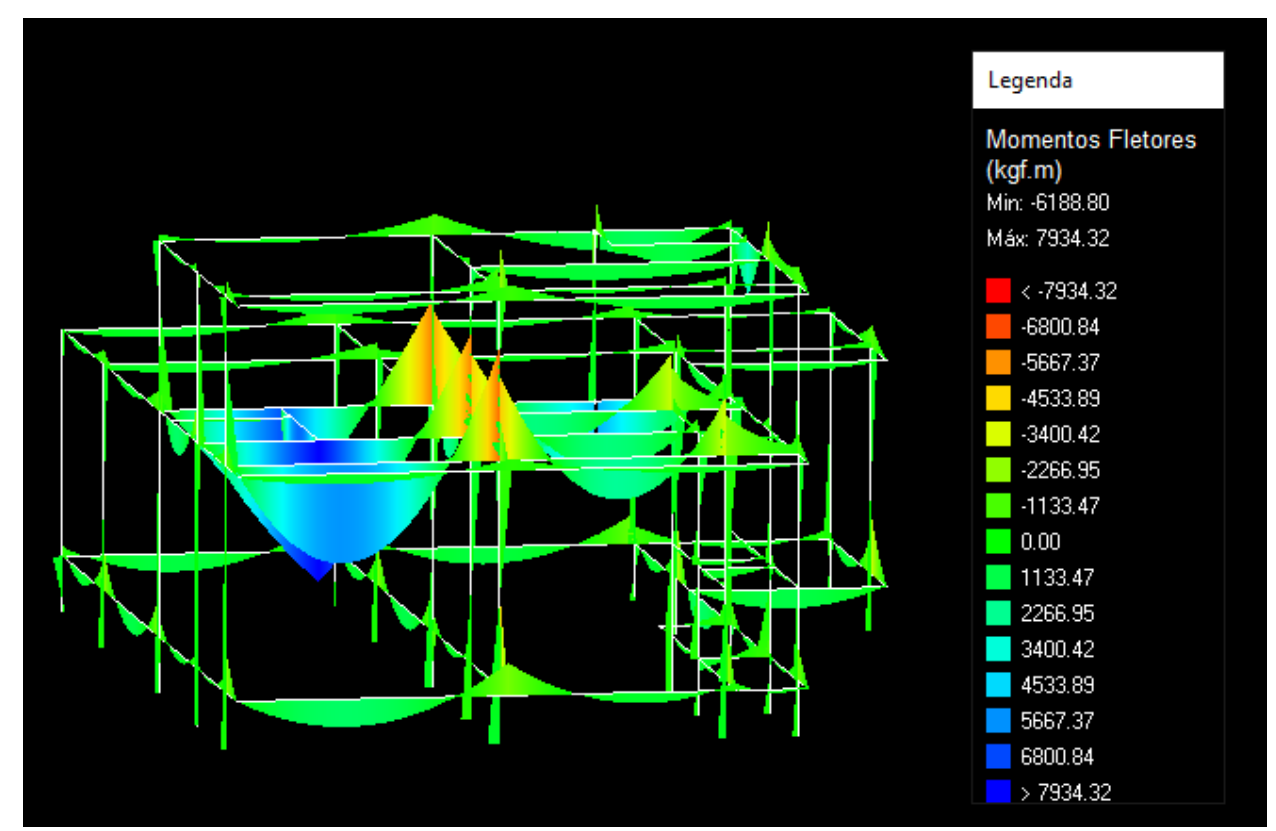

Figura 06. Momentos fletores considerando pórtico com apoio indeslocável.

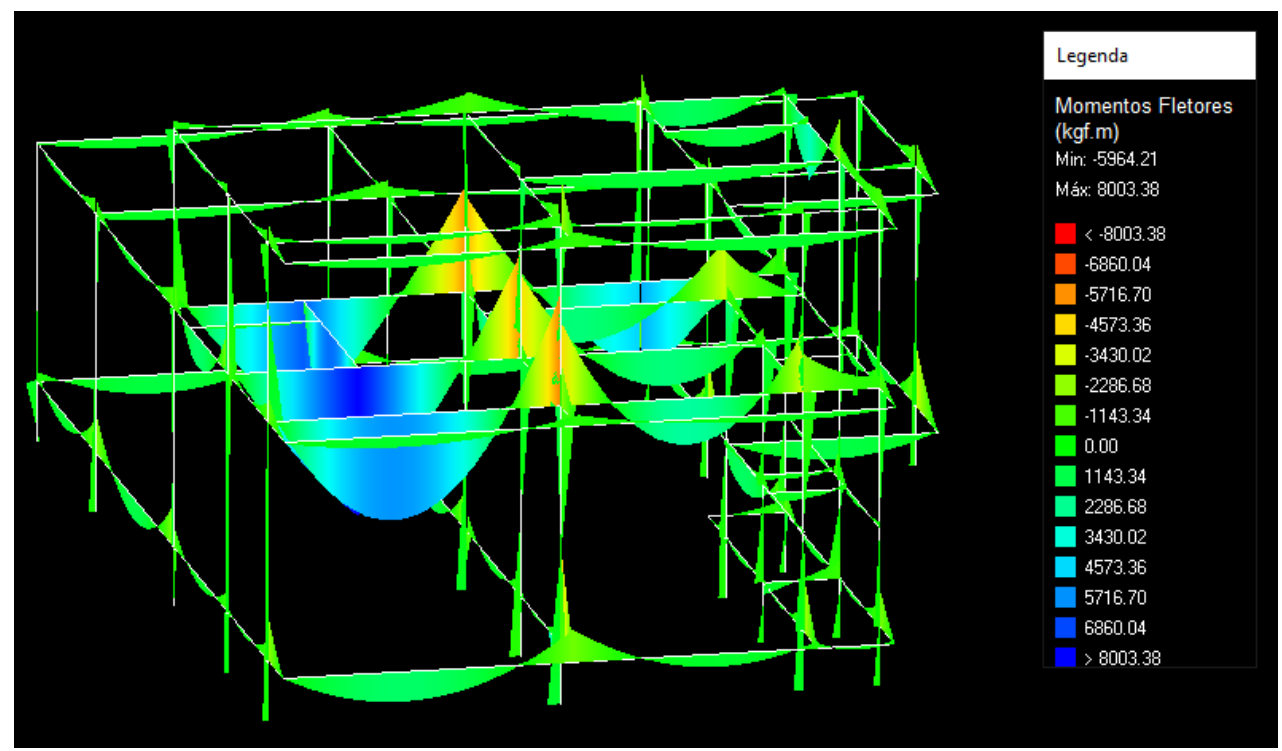

Figura 07. Momentos fletores considerando pórtico com apoio elástico.

Outra importante alteração, comparando as duas hipóteses, foi o coeficiente " $\gamma_{z}$ (gama-z)", tendo por principal objetivo classificar a estrutura quanto à deslocabilidade dos nós, a fim de destacar o quão significativos são os esforços de 2a ordem globais para efeitos de cálculo. Nesse sentido, se o valor de $\gamma_{z}$ for menor que 1,10 , dispensa a verificação dos efeitos de $2^{\circ}$ ordem na estrutura. Na edificação analisada acontenceu que para os apoios indeslocáveis, o coeficiente gama-z foi a 1,09. Já considerando os apoios elástico, o coeficiente de gama-z foi equivalente a 1.10. Em outras palavras, devido a consideração do apoio elástico na edificação, percebeu-se a necessidade de considerar os esforços de $2^{\circ}$ ordem, conforme diretrizes da NBR 6118:2014. 


\section{Conclusões}

Conforme pode ser constatado, a influência da interação solo estrutura, mesmo em edificações de pequeno porte, foi considerável. Houve uma redistribuição dos esforços, conforme verificado com os carregamentos nos pilares e momentos fletores no pórtico da estrutura.

Essas alterações podem reduzir o desempenho da edificação, ocorrendo possibilidade de fissura devido a insuficiência de armaduras nas peças estruturas. Da mesma forma, pode-se falar do coeficiente gama-z de análise dos efeitos de segunda ordem. Com a consideração da interação solo estrutura, houve a necessidade de analisar os efeitos de $2^{\circ}$ ordem, conforme NBR 6118:2014. É importante ressaltar que embora pequenas alterações foram trazidas, mas em alguns casos, principalmente em solos moles, essas diferenças poderão trazer grandes prejuízos.

\section{Referências Bibliográficas}

BOLDO, P., Análise Quantitativa de Estruturas de Concreto Armado de Edificações no Âmbito do Exército Brasileiro. Dissertação de Mestrado, Publicação E.DM-001A/02, Departamento de Engenharia Civil e Ambiental, Universidade de Brasília, Brasília, DF, 2002, 295 p.

MEYERHOF, G. G., 1953, "Some Recent Foundation Research and its Application to Design", Structural Engineering, v. 31, pp. 151-167, Londres.

CHAMECKI, S. Consideração da rigidez no cálculo de recalques de fundações. In: CONGRESSO BRASILEIRODE MECÂNICA DOS SOLOS E ENGENHARIA DE FUNDAÇÕES, 1., 1956, Porto Alegre. Anais... Porto Alegre: Ipsis Grafica e Editora, 1956. p. 35-80.

CHAMECKI, S. Consideração da rigidez no cálculo de recalques de fundações. In: CONGRESSO BRASILEIRO DE MECÂNICA DOS SOLOS E ENGENHARIA DE FUNDAÇÕES, 1., 1956, Porto Alegre. Anais... Porto Alegre: Ipsis Grafica e Editora, 1956. p. 35-80.

GUSMÃO, A. D., 1990, "Estudo da Interação Solo-Estrutura e sua Influência em Recalques de Edificações", Tese de M.Sc., COPPE/UFRJ, Rio de Janeiro, RJ, Brasil.

AOKI, N.; CINTRA, J. C. A.; ALBIERO, J. H., 2003, “Tensão admissível em fundações diretas”, Editora Rima, São Carlos, $135 \mathrm{p}$.

PERLOFF, W.H. Pressure distribution and settlement. In: WINTERKORN, H.F.; FANG, H.Y. Foundation engineering handbook. New York: Van Nostrand Reinhold, 1975. p. 148-196

SANTOS, M. F. S; FERREIRA, C.V.; BRITO, D. C.; MATOS, W. E. C.; SOUSA, F.D.S. Interpretação e análise comparativa de resultados das sondagens de simples reconhecimento (SPT) de solos do Piauí e do Maranhão. In: Congresso Brasileiro de Mecânica dos Solos, 2018. Anais... Bahia, Salvador: ABMS, 2018.

ASSOCIAÇÃO BRASILEIRA DE NORMAS TÉCNICAS Projeto de estruturas de concreto - Procedimento. - NBR 6118, Rio de Janeiro, 2014. 